\title{
The effects of smoking on periodontal disease: An evidence-based comprehensive literature review
}

\author{
Mahmoud Abu-Ta’a \\ Department of Oral Surgery \& Periodontology, Faculty of Dentistry, Arab American University, West Bank, Palestine \\ Email:_mahmoud_abutaa@yahoo.com
}

Received 8 December 2013; revised 9 January 2014; accepted 19 January 2014

Copyright (C) 2014 Mahmoud Abu-Ta’a. This is an open access article distributed under the Creative Commons Attribution License, which permits unrestricted use, distribution, and reproduction in any medium, provided the original work is properly cited. In accordance of the Creative Commons Attribution License all Copyrights (c) 2014 are reserved for SCIRP and the owner of the intellectual property Mahmoud Abu-Ta’a. All Copyright @ 2014 are guarded by law and by SCIRP as a guardian.

\section{ABSTRACT}

The direct link between smoking, lung diseases, cancer, cardiovascular disease and poor pregnancy outcomes, such as miscarriage and low birth weight, has been extensively studied. In the past three decades, there has also been an increasing awareness of the impact of smoking on periodontal disease. Smoking is considered the major environmental risk factor in the prevalence, extent and severity of periodontal disease. This review article will attempt to build on previous studies in the periodontal literature in order to present an evidence-based comprehensive literature review on the effects of smoking on periodontal disease.

\section{KEYWORDS}

\section{Smoking; Periodontitis; Periodontal Disease; Tobacco; Cigarette Smoking}

\section{INTRODUCTION}

Periodontitis is the result of complex interrelationships between infectious agents and host factors. Environmental, acquired, and genetic risk factors modify the expression of disease and may therefore affect the onset or progression of periodontitis [1]. Among the environmental risk factors, tobacco smoking has been found to be associated with an increased prevalence and severity of periodontal disease [2].

For many years, smoking has been linked to lung disease, cancer, cardiovascular disease, and poor pregnancy outcomes, such as miscarriage and low birth weight [3]. Over the past two decades, it has also been recognized that smoking is associated with periodontal disease. As early as the 1940s, Pindborg noted that acute necrotizing ulcerative gingivitis was associated with smoking in the Danish Royal Marines [4].
It is now well established that tobacco use is the most important, if not the most important, preventable risk factor in the incidence and progression of periodontal diseases [5-7]. In addition, tobacco use has a negative adverse effect on the full spectrum of periodontal treatment approaches, ranging from mechanical debridement, local and systemic antimicrobial therapy to periodontal surgery including regenerative procedures and oral implants [7].

Indeed, Haber has described a discrete, smoking-specific disease entity—smoking associated periodontitisthat is characterized by fibrotic gingiva, limited gingival redness and oedema relative to disease severity, proportionally greater pocketing in anterior and maxillary lingual sites, gingival recession at anterior sites, and a lack of association between periodontal status and the level of oral hygiene [8].

Evidence of risk factor status is strengthened by the ability to demonstrate a dose-response and "years of exposure" to tobacco products as risk factors for periodontal disease [6,9]. It remains challenging, however, to determine the strength of smoking as a risk factor owing to inherent problems in measuring accurately a subject's exposure to tobacco [10-12]. In general, therefore, there is a substantial body of evidence to support the observation that the more a patient smokes, the greater the degree of periodontal disease. The logical corollary then is that treatments for periodontal disease are likely to be more efficacious in non-smokers than in smokers. In other words, this means when the effect of the level of cigarette consumption is considered, it seems that the response to periodontal therapy is related to the amount of cigarettes smoked [13], and that previous smokers (quit-smokers) have a similar response to treatment compared to nonsmokers [13,14].

Taking into consideration the vast body of medical literature that describes the biological basis of smoking, its pathogenic mechanisms in addition to its clinical and ep- 
idemiological aspects, this review will attempt to build on previous studies in the periodontal literature in order to present an evidence-based comprehensive literature review on the effects of smoking on periodontal disease. To identify literature regarding the relationship between smoking and periodontal disease, a MEDLINE literature search has been conducted using the key words smoking, tobacco, cigarette smoking and environmental/life-style factors in combination with periodontitis or periodontal disease. Searches were limited to the English language literature; no more restrictions were applied.

\section{EVIDENCE-BASED REVIEW}

\subsection{Effects of Smoking on the Prevalence and Severity of Periodontal Diseases}

Bergstrom [15] demonstrated that tobacco use is a significant risk factor for the development of periodontal diseases. Bergstrom and colleagues [16] showed that disease severity increases with the frequency of smoking. Smoking is also associated with an increased risk of periodontal attachment loss and formation of periodontal pockets, as well as alveolar bone loss. The adverse effects of smoking on the periodontium correlate well with both the quantity of daily consumption and the duration as shown by Califano et al. [17] and Codd and coworkers [18]. Grossi and colleagues [5] examined the relationship between smoking and attachment loss and demonstrated a dose dependent response in which more severe attachment loss occurred in smokers compared with nonsmokers, ranging from $2.05 \mathrm{~mm}$ for light smokers to 4.75 $\mathrm{mm}$ in heavy smokers. These findings support those of Alpagot and colleagues [19], who reported that probing depth was significantly correlated with "pack years" (i.e., packs of cigarettes smoked per day multiplied by the number of years the subject has smoked). Furthermore years of exposure to tobacco products have been shown to be a statistically significant risk factor for periodontal disease in 1156 community-dwelling New England elders, regardless of other social and behavioral factors [20].

Expressed as a percentage of tooth root length in 723 dentate adults, alveolar bone height was shown to be significantly lower in individuals smoking more than $5 \mathrm{~g}$ of tobacco per day compared with those smoking between 1 and $5 \mathrm{~g}$ of tobacco per day [21]. Norderyd and Hugoson examined 547 Swedish adults and found that moderate to heavy smoking (greater than or equal to 10 cigarettes per day) was associated with severe periodontitis, but that light smoking ( $<10$ cigarettes per day) was not [22].

Smokers were recorded to have a 2.5 to 3.5 times greater risk of severe periodontal attachment loss [15]. In analyses that adjusted for different oral hygiene habits, patient age, sex, and socio-economic level, smokers had deeper periodontal pockets, increased alveolar bone loss, increased tooth mobility, and more tooth loss than did non-smokers [5]. In addition, emotional stress and poor oral hygiene seem to play an important interactive role with tobacco smoking [23]. Acute necrotising gingivitis is also strongly correlated with tobacco use [24]. Although the precise cause of this infection remains unknown; it tends to occur most frequently in teenagers and young adults. Some patients with acute necrotising gingivitis have defective neutrophil function, thereby allowing bacterial, or possibly viral (cytomegalovirus) invasion of gingival tissues [25]. The gingival bleeding in smokers is "less severe" than in non-smokers, which could be related to the vasoconstrictive effect of the nicotine. The main vasoconstrictive property of nicotine exerts its effect at the end-arterial vasculature of the gingivae [26]. And other tobacco components can also induce tissue necrosis and ulceration seen in the disease.

Smokeless tobacco users have an incidence of gingivitis and gingival bleeding that is similar to the incidence among non-users. Nevertheless, use of this form of tobacco is known to produce a painless loss of gingival tissues and alveolar bone destruction in the area of chronic tobacco contact, as a result of collagen breakdown due to increased release of collagenase [27].

In another study performed in the US exploring the relationship between periodontitis and cigarette smoking; where more than 12,000 dentate individuals over the age of 18 years participated as part of the National Health and Nutrition Examination Survey (NHANES III) smokers were on average 4 times as likely to have periodontitis as persons who had never smoked. Former smokers were 1.68 times more likely to have periodontitis than persons who had never smoked [28]. This study also demonstrated a dose-response relationship between cigarettes smoked per day and the odds of having periodontitis. In subjects smoking 9 cigarettes or less per day the odds for having periodontitis was 2.79 whereas subjects smoking 31 cigarettes per day or more were nearly 6 times more likely to have periodontitis. With former smokers, the odds of having periodontitis declined with the number of years since quitting.

These data are consistent with the findings of other studies. A meta-analysis of data from six studies involving 2361 subjects indicated that current smokers were nearly 3 times more likely to have severe periodontitis than nonsmokers [29]. Other studies indicated that older adult smokers are approximately 3 times more likely to have severe periodontal disease [30] while young adults between the ages of 19 to 30 years who smoke are 3.8 times more likely to have periodontitis than nonsmokers [2].

Less information is available on the effects of cigar and pipe smoking, but it appears that effects similar to cigarette smoking may be observed with this form of to- 
bacco use [31-33]. On the other hand smokeless tobacco use has been associated with ora leukoplakia and carcinoma [34].

Of greater interest is the observation that former smokers have less risk for periodontitis than current smokers but more risk than nonsmokers and that the risk for periodontitis decreases with the increasing number of years since quitting smoking [28]. This suggests that the effects of smoking on periodontal disease progression are reversible with smoking cessation and that smoking cessation programs should be an integral component of periodontal education and therapy.

\subsection{Effects of Nicotine on the Periodontal Tissues}

While nicotine is the primary psychoactive component, and addiction to it is the main reason for people subjecting themselves to frequent and high doses over many years, one must appreciate that tobacco smoke contains thousands of different compounds. Many of these are directly noxious/poisonous to living organisms and cells, and nicotine may be unfairly blamed for most of these properties. Moreover, it is also very important to appreciate that most of the harmful effects of tobacco products will result from systemic exposure through absorption in the lungs rather than topical absorption in the oral cavity [35]. A regular heavy smoker exposes himself/herself to these compounds many times per day for several minutes at a time. Although increasing evidence is being presented for the harmful effects of passive smoking, the periodontal literature is generally confined to active smoking. Many smokers develop the habit in their teenage years and continue it throughout their life. No other drug is administered so frequently or over such a time period as smoking. This is to emphasize the fact that the detrimental effects on the periodontium are derived from longterm chronic exposure and bear little relationship with the effects that can be measured on a single exposure [10]. Cotinine, a metabolite of nicotine, can be measured in the serum/plasma and saliva, and is a better measure of tobacco smoke exposure as it has a longer half-life than nicotine (18 h compared with 1 - 2 h). Smokers would be expected to have serum cotinine levels of over $14 \mathrm{ng} / \mathrm{ml}$, and this could be as high as $1000 \mathrm{ng} / \mathrm{ml}$. Resting plasma nicotine levels are much lower (5 - $50 \mathrm{ng} / \mathrm{ml}$ ), and are maintained by the individual to satisfy their craving for nicotine. Because nicotine is so rapidly absorbed from the lung and transport to the brain is rapid, very high peak levels can be measured in the brain. It is important to understand these variations in relation to levels tested in in-vitro experiments [26].

Some early studies suggested that smokers experienced less gingival bleeding than non-smokers [36,37]. This observation was confirmed in a comparative study of 10 heavy smokers (at least 20 cigarettes per day) and 10 non-smokers who had similar levels of periodontitis [38]. These authors cited the potential vasoconstrictive effect of nicotine previously reported by Clarke [26]. The reduced bleeding on probing was further demonstrated in a study by Bergstrom \& Bostrom [39]. Gingival bleeding was lower in 130 smokers (median [interquartile range, IQR] bleeding score 19.0 [13.0]) than 113 non-smokers (median [IQR] bleeding score 32.0 [20.3]), with similar levels of periodontitis $(p<0.001)$.

Tobacco smoke contains carbon monoxide, which is detectable in the breath of smokers and can be used to assess compliance in quit-smoking programmes [10]. Oxygen saturation of haemoglobin is affected and attempts have been made to measure this in the gingival tissue of smokers and non-smokers. Hanioka and coworkers [40] showed variable results. In healthy gingiva, smokers did appear to have lower oxygen saturation, determined using tissue reflectance spectrophotometry, whereas in the presence of inflammation, the converse was shown. The same group of workers [40] also examined the oxygen tension in the pockets of 34 non-smokers and 27 heavy smokers with mild to moderate periodontitis. They showed that the pocket oxygen tension was significantly lower in smokers (mean $21.9 \mathrm{~mm} \mathrm{Hg}$ ) compared with non-smokers (mean $33.4 \mathrm{~mm} \mathrm{Hg}$ [ $p<0.0001]$ ). This could have an impact on the pocket microflora.

The vasculature has also been examined in histological and immunocytochemical studies. In a very limited study of one histological section from three smokers and four non-smokers, Mirbod and coworkers [41] found that there were a high proportion of small vessels compared with large vessels in smokers compared with non-smokers, but no difference in the vascular density. The region chosen for study was the connective tissue beneath the external gingival epithelium, which was therefore remote from the pocket wall/sulcus and the inflammatory lesion. SÖnmez and colleagues [42] did not show differences in the density or number of Factor VIII labelled vessels in gingival tissues obtained at the time of periodontal surgery from 38 smokers and 36 nonsmokers. The orientation and location of the specimens were not described. A more comprehensive histological comparison of smokers and non-smokers was presented by Rezavandi and coworkers [43], who labelled the vessels by immunocytochemical staining to the von Willebrand factor, ICAM-1 and E-Selectin. They reported that a significantly larger number of vessels were observed in inflamed tissues of nonsmokers than smokers $(p<0.05)$.

Baab \& Öberg [44] were the first researchers to question the vasoconstrictive action of nicotine (from cigarette smoking) on gingival tissues. In a Laser Doppler Flow (LDF) study of 12 young regular smokers, they showed that gingival blood flow rose by about $25 \%$ dur- 
ing smoking, was maintained for $5 \mathrm{~min}$. and then gradually declined to baseline values. This was associated with an increase in heart rate and systolic and diastolic blood pressure. They confirmed that the blood flow to the skin of the forearm did decrease slightly, demonstrating the differences in response between peripheral skin responses and those in the head and neck. It was interesting to note that 3 of their subjects felt light headed after smoking, suggesting that the inhalation dose was greater than they normally experienced.

Animal studies have shown that local nicotine delivery negatively impacts bone healing [45], which may be related to inhibited expression of various growth factors [46] and delayed revascularization [47]. These findings might help explain the diminished treatment response to surgical periodontal procedures, especially that involving tissue regeneration.

This means that tobacco smoking may exert a masking effect on gingival symptoms of inflammation, which might give smoking patients a false sense of assurance of gingival health [39]. Smoking upregulates the expression of pro-inflammatory cytokines, such as interleukin-1, this contributes to increased tissue damage and alveolar bone resorption [48]. Interleukin-1 genotypepositive smokers are more susceptible to severe adult periodontitis [48].

\subsection{Effects of Smoking on the Etiology and Pathogenesis of Periodontal Disease}

The increased prevalence and severity of periodontal destruction associated with smoking suggests that the hostbacterial interactions normally seen in chronic periodontitis are altered, resulting in more aggressive periodontal breakdown. This imbalance between bacterial challenge and host response may be due to changes in the composition of the subgingival plaque, with increases in the numbers and/or virulence of pathogenic organisms; changes in the host response to the bacterial challenge; or a combination of both.

\subsection{Physiology}

The clinical signs of inflammation are less pronounced in smokers when compared with nonsmokers [49,50]. These observations may be due to alterations in the inflammatory response in smokers or due to alterations in the vascular response of the gingival tissues. Although no significant differences in the vascular density of healthy gingiva have been observed between smokers and nonsmokers, the response of the microcirculation to plaque accumulation appears to be altered in smokers when compared with nonsmokers. With developing inflammation, increases in gingival crevicular fluid flow [49], bleeding on probing [49], and gingival blood vessels were less in smokers when compared with nonsmokers. In addition, the oxygen concentration in healthy gingival tissues appears to be less in smokers than nonsmokers, although this condition is reversed in the presence of moderate inflammation [51]. Subgingival temperatures are lower in smokers than nonsmokers [52] and recovery from the vasoconstriction caused by local anaesthetic administration takes longer in smokers [53]. These cumulative data suggest the presence of significant alterations in the gingival microvasculature of smokers when compared with nonsmokers and that these changes lead to decreased blood flow and decreased clinical signs of inflammation when disease progresses.

\subsection{Microbiology}

Several studies have explored the changes that may occur in subgingival plaque as a result of smoking with conflicting and inconclusive results. In a study of 142 patients with chronic periodontitis, plaque samples from deep pockets $(>6 \mathrm{~mm})$ showed no differences in the counts of Aggregatibacter actinomyceterncomitans, Porphyromonas gingivalis, and Prevotella intermedia [54]. In a similar study of 615 patients, the prevalence of $A$. actinomyceterncomitans, $P$. gingivalis, $P$. intermedia, and Eikenella corrodens was not found to be significantly different between smokers and nonsmokers using immunoassay [55]. In contrast, other studies have shown differences in the microbial composition of subgingival plaque between smokers and nonsmokers. In a study of 798 subjects with different smoking histories, it was found that smokers had significantly higher levels of $T$. forsythensis and that smokers were 2.3 times more likely to harbor $T$. forsythensis than nonsmokers and former smokers [55]. Of particular interest was the observation that smokers do not respond to mechanical therapy as well as nonsmokers and that this is associated with increased levels of T. forsythensis, A. actinomyceterncomitans, and $P$. gingivalis remaining in the pockets after therapy in the smoking group when compared with non-smokers [14, 56-58]. Many discrepancies between the findings of microbiologic studies are a function of the methodology involved, including bacterial counts versus proportions or prevalence of bacteria, number of sites sampled and the pocket depths selected, the sampling technique, the disease status of the subject, and the methods of bacterial enumeration and data analysis [57]. In an attempt to overcome some of these problems, another study sampled subgingival plaque from all teeth with the exception of third molars in 272 adult subjects, including 50 current smokers, 98 past smokers, and 124 nonsmokers [59]. Using checkerboard DNA-DNA hybridization technology to screen for 29 different subgingival species; it was 
found that members of the orange and red complexes including Eikenella nodatum, Fusobacterium nucleatum ss. vincentii, P. intermedia, Peptostreptococcus micros, Prevotella nigrescens, $T$. forsythensis, $P$. gingivalis, and Treponema denticola were significantly more prevalent in current smokers than in non-smokers and former smokers. Of interest was that the increased prevalence of these periodontal pathogens was due to an increased colonization of shallow sites (pocket depth $<4 \mathrm{~mm}$ ) with no differences between smokers, former smokers, and nonsmokers in pockets deeper than $4 \mathrm{~mm}$ [59]. In addition, these pathogenic bacteria were more prevalent in the maxilla than the mandible. There are also reports of higher proportions and/or prevalence of exogenous [60] or commensal [61] flora in moderate to deep probing depths in smokers that point towards an adverse effect of smoking on the host response. This concept is also supported by the persistence of periodontal bacteria in smokers following scaling and root planning [14,57,61-63]. These data suggest that smokers have a greater extent of colonization by periodontal pathogens than nonsmokers or former smokers and that this colonization may lead to an increased prevalence of periodontal breakdown.

\subsection{Immunology}

The immune response of the host to plaque accumulation is essentially protective. In periodontal health and gingivitis, a balance exists between the bacterial challenge of plaque and the immune response from within the gingival tissues, with no resulting loss of periodontal support. In contrast, periodontitis appears to be associated with an alteration in the host-bacterial balance that may be initiated by changes in the bacterial composition of subgingival plaque, changes in the immune response, or a combination of both elements. Smoking exerts a major effect on the protective elements of the immune response, resulting in an increase in the extent and severity of periodontal destruction. The deleterious effects of smoking appear to be due in part to a down regulation of the immune response to bacterial challenge [64]. The neutrophil is an important component of the host response to bacterial infection, and alterations in neutrophil number or function may result in localized and/or systemic infections. Critical functions of neutrophils include chemotaxis (directed locomotion from the blood stream to the site of infection), phagocytosis (internalization of foreign particles such as bacteria), and killing using oxidative and nonoxidative mechanisms. Neutrophils, obtained from the peripheral blood or saliva of smokers or exposed in vitro to whole tobacco smoke or nicotine, have been shown to demonstrate functional alterations in chemotaxis, phagocytosis, and the oxidative burst. Smoking has been shown to impair the chemotaxis and phagocytosis of neutrophils obtained from the oral cavity $[48,65]$ and in vitro studies of the effects of tobacco products on neutrophils have shown detrimental effects on cell movement and the oxidative burst [66-69]. However, it should also be noted that the majority of studies have reported no major differences of neutrophil numbers in the pocket [70]. However, in lung tissues exposed to smoke there are increased numbers of neutrophils within the tissue itself [71]. In addition, smokers have an increased number of $\mathrm{T}$ cells in the periodontal tissues [48], another host response cell that uses the integrin/selectin system to migrate into tissues. These series of observations indicate that neutrophils in smokers may be stimulated to migrate into the periodontal tissues, but once in the tissues, the continual exposure to smoke may impair their further progress into the periodontal pocket. Nevertheless, these neutrophils in tissue would still be exposed to intermittent acute higher exposure of tobacco substances that could penetrate into the superficial tissue and trigger destructive processes. In addition, the production of antibody essential for phagocytosis and killing of bacteria, specifically lgG2 levels to periodontal pathogens, has been reported to be reduced in smokers versus non-smokers with periodontitis $[17,72,73]$, suggesting that smokers may have reduced protection against periodontal infection. In contrast, elevated levels of TNF- $\alpha$ have been demonstrated in the gingival crevicular fluid of smokers' as well as elevated levels of PGEg, neutrophil elastase, and matrix metalloproteinase [15]. In vitro studies also have demonstrated that exposure to nicotine increases the secretion of PGEz by monocytes in response to LPS [74]. These data suggest that smoking may impair the response of neutrophils to periodontal infection but may also increase the release of tissue-destructive enzymes.

It is interesting to know that for patients who use tobacco as a smoke product, such as cigarettes, cigars and pipes, there are two levels of tobacco exposure that are encountered; these can be termed "chronic" and "acute" smoke exposures [67,75-77].

In the smoker there are "chronic" low levels of tobacco products in serum, saliva, gingival crevice fluid, and within the cells and extracellular matrix of the periodontal tissue itself. These low concentrations of tobacco may have one type of effect on the host response [64]. However, during the act of smoking, concentrations of tobacco products, several hundred to thousands of times higher, are encountered in the saliva, gingival crevice fluid and periodontal tissues $[67,77,78]$. These much higher concentrations may have different effects on cells and other elements of the host response when compared with the longer-term chronic levels [64]. Such higher concentrations have been shown to impair fibroblast attachment and collagen synthesis which may in turn impair the hea- 
ling response in periodontal diseases in smokers [64].

\section{CONCLUSION}

In view of the fact that smokers are two- to eight-fold more likely to have periodontitis than nonsmokers, smoking cessation should be an important treatment consideration for periodontal patients. This fact can be useful in patient education and may provide encouragement to patients contemplating cessation. Dental professionals are well positioned to provide smoking cessation advice to their patients because patients are likely to visit their periodontologists/dentists more often than their physician. Therefore, close collaboration of dentists/periodontologists and physicians is recommended in the treatment of smoking patients.

\section{REFERENCES}

[1] Page, R.C. and Kornman, K.S. (1997) The pathogenesis of human periodontitis: An introduction. Periodontology, 14, 9-11. http://dx.doi.org/10.1111/j.1600-0757.1997.tb00189.x

[2] Haber, J., Wattles, J., Crowley, M., Mandell, R., Joshipura, K. and Kent, R.L. (1993) Evidence for cigarette smoking as a major risk factor for periodontitis. Journal of Periodontology, 64, 16-23.

http://dx.doi.org/10.1902/jop.1993.64.1.16

[3] Wald, N.J. and Hackshaw, A.K. (1996) Cigarette smoking: An epidemiological overview. British Medical Bulletin, 52, 3-11.

http://dx.doi.org/10.1093/oxfordjournals.bmb.a011530

[4] Pindborg, J.J. (1949) Tobacco and gingivitis; correlation between consumption of tobacco, ulceromembranous gingiivitis and calculus. Journal of Dental Research, 28, 460463. http://dx.doi.org/10.1177/00220345490280050601

[5] Grossi, S.G., Zambon, J.J., Ho, A.W., Koch, G., Dunford, R.G., Machtei, E.E., Norderyd, O.M. and Genco, R.J. (1994) Assessment of risk for periodontal disease. I. Risk indicators for attachment loss. Journal of Periodontology, 65, 260-267. http://dx.doi.org/10.1902/jop.1994.65.3.260

[6] Grossi, S.G., Genco, R.J., Machtei, E.E., Ho, A.W., Koch, G., Dunford, R., Zambon, J.J. and Hausmann, E. (1995) Assessment of risk for periodontal disease. II. Risk indicators for alveolar bone loss. Journal of Periodontology, 66, 23-29. http://dx.doi.org/10.1902/jop.1995.66.1.23

[7] Johnson, G.K. and Hill, M. (2004) Cigarette smoking and the periodontal patient. Journal of Periodontology, 75, 196-209. http://dx.doi.org/10.1902/jop.2004.75.2.196

[8] Haber, J. (1994) Smoking is a major risk factor for periodontitis. Current Opinion in Periodontology, 12-18.

[9] Martinez-Canut, P., Lorca, A. and Magan, R. (1995) Smoking and periodontal disease severity. Journal of Clinical Periodontology, 22, 743-749. http://dx.doi.org/10.1111/j.1600-051X.1995.tb00256.x

[10] Scott, D.A., Palmer, R.M. and Stapleton, J.A. (2001) Doseyears as an improved index of cumulative tobacco smoke exposure. Medical Hypotheses, 56, 735-736. http://dx.doi.org/10.1054/mehy.2001.1238

[11] Molloy, J., Wolff, L.F., Lopez-Guzman, A. and Hodges, J.S. (2004) The association of periodontal disease parameters with systemic medical conditions and tobacco use. Journal of Clinical Periodontology, 31, 625-632. http://dx.doi.org/10.1111/j.1600-051X.2004.00539.x

[12] Persson, R.E., Kiyak, A.H., Wyatt, C.C., Macentee, M. and Persson, G.R. (2005) Smoking, a weak predictor of periodontitis in older adults. Journal of Clinical Periodontology, 32, 512-517. http://dx.doi.org/10.1111/j.1600-051X.2005.00701.x

[13] Kaldahl, W.B., Johnson, G.K., Patil, K.D. and Kalkwarf, K.L. (1996) Levels of cigarette consumption and response to periodontal therapy. Journal of Periodontology, 67, 675-681. http://dx.doi.org/10.1902/jop.1996.67.7.675

[14] Grossi, S.G., Zambon, J., Machtei, E.E., Schifferle, R., Andreana, S., Genco, R.J., Cummins, D. and Harrap, G. (1997) Effects of smoking and smoking cessation on healing after mechanical periodontal therapy. The Journal of the American Dental Association, 128, 599-607.

[15] Bergstrom, J. (1989) Cigarette smoking as risk factor in chronic periodontal disease. Community Dentistry and Oral Epidemiology, 17, 245-247. http://dx.doi.org/10.1111/j.1600-0528.1989.tb00626.x

[16] Bergstrom, J., Eliasson, S. and Dock, J. (2000) Exposure to tobacco smoking and periodontal health. Journal of Clinical Periodontology, 27, 61-68. http://dx.doi.org/10.1034/j.1600-051x.2000.027001061.x

[17] Califano, J.V., Schifferle, R.E., Gunsolley, J.C., Best, A.M., Schenkein, H.A. and Tew, J.G. (1999) Antibody reactive with Porphyromonas gingivalis serotypes K1-6 in adult and generalized early-onset periodontitis. Journal of Periodontology, 70, 730-735. http://dx.doi.org/10.1902/jop.1999.70.7.730

[18] Codd, E.E., Swim, A.T. and Bridges, R.B. (1987) Tobacco smokers' neutrophils are desensitized to chemotactic peptide-stimulated oxygen uptake. Journal of Laboratory and Clinical Medicine, 110, 648-652.

[19] Alpagot, T., Wolff, L.F., Smith, Q.T. and Tran, S.D. (1996) Risk indicators for periodontal disease in a racially diverse urban population. Journal of Clinical Periodontology, 23, 982-988. http://dx.doi.org/10.1111/j.1600-051X.1996.tb00524.x

[20] Jette, A.M., Feldman, H.A. and Tennstedt, S.L. (1993) Tobacco use: A modifiable risk factor for dental disease among the elderly. American Journal of Public Health, 83, 1271-1276. http://dx.doi.org/10.2105/AJPH.83.9.1271

[21] Wouters, F.R., Salonen, L.W., Frithiof, L. and Hellden, L.B. (1993) Significance of some variables on interproximal alveolar bone height based on cross-sectional epidemiologic data. Journal of Clinical Periodontology, 20, 199-206. http://dx.doi.org/10.1111/j.1600-051X.1993.tb00344.x

[22] Norderyd, O. and Hugoson, A. (1998) Risk of severe periodontal disease in a Swedish adult population. A crosssectional study. Journal of Clinical Periodontology, 25, 1022-1028. 
http://dx.doi.org/10.1111/j.1600-051X.1998.tb02408.X

[23] Horning, G.M. and Cohen, M.E. (1995) Necrotizing ulcerative gingivitis, periodontitis, and stomatitis: Clinical staging and predisposing factors. Journal of Periodontology, 66, 990-998. http://dx.doi.org/10.1902/jop.1995.66.11.990

[24] Johnson, B.D. and Engel, D. (1986) Acute necrotizing ulcerative gingivitis. A review of diagnosis, etiology and treatment. Journal of Periodontology, 57, 141-150. http://dx.doi.org/10.1902/jop.1986.57.3.141

[25] Slots, J. and Contreras, A. (2000) Herpesviruses: A unifying causative factor in periodontitis? Oral Microbiological Immunology, 15, 277-280. http://dx.doi.org/10.1034/j.1399-302x.2000.150501.x

[26] Clarke, N.G., Shephard, B.C. and Hirsch, R.S. (1981) The effects of intra-arterial epinephrine and nicotine on gingival circulation. Oral Surgery, Oral Medicine, Oral Pathology, Oral Radiology, 52, 577-582. http://dx.doi.org/10.1016/0030-4220(81)90071-2

[27] Tipton, D.A. and Dabbous, M.K. (1995) Effects of nicotine on proliferation and extracellular matrix production of human gingival fibroblasts in vitro. Journal of Periodontology, 66, 1056-1064.

http://dx.doi.org/10.1902/jop.1995.66.12.1056

[28] Tomar, S.L. and Asma, S. (2000) Smoking-attributable periodontitis in the United States: Findings from NHANES III. National Health and Nutrition Examination Survey. Journal of Periodontology, 71, 743-751. http://dx.doi.org/10.1902/jop.2000.71.5.743

[29] Papapanou, P.N. (1996) Periodontal diseases: Epidemiology. Annals of Periodontology, 1, 1-36. http://dx.doi.org/10.1902/annals.1996.1.1.1

[30] Locker, D. and Leake, J.L. (1993) Periodontal attachment loss in independently living older adults in Ontario, Canada. Journal of Public Health Dentistry, 53, 6-11. http://dx.doi.org/10.1111/j.1752-7325.1993.tb02664.x

[31] Feldman, R.S., Bravacos, J.S. and Rose, C.L. (1983) Association between smoking different tobacco products and periodontal disease indexes. Journal of Periodontology, 54, 481-487.

http://dx.doi.org/10.1902/jop.1983.54.8.481

[32] Feldman, R.S., Alman, J.E. and Chauncey, H.H. (1987) Periodontal disease indexes and tobacco smoking in healthy aging men. Gerodontics, 3, 43-46.

[33] Krall, E.A., Garvey, A.J. and Garcia, R.I. (1999) Alveolar bone loss and tooth loss in male cigar and pipe smokers. Journal of the American Dental Association, 130, 57-64.

[34] Creath, C.J., Cutter, G., Bradley, D.H. and Wright, J.T. (1991) Oral leukoplakia and adolescent smokeless tobacco use. Oral Surgery, Oral Medicine, Oral Pathology, 72, 3541. http://dx.doi.org/10.1016/0030-4220(91)90186-G

[35] Palmer, R.M., Scott, D.A., Meekin, T.N., Poston, R.N., Odell, E.W. and Wilson, R.F. (1999) Potential mechanisms of susceptibility to periodontitis in tobacco smokers. Journal of Periodontal Research, 34, 363-369. http://dx.doi.org/10.1111/j.1600-0765.1999.tb02267.x

[36] Palmer, R.M., Wilson, R.F., Hasan, A.S. and Scott, D.A. (2005) Mechanisms of action of environmental factors- tobacco smoking. Journal of Clinical Periodontology, 32, 180-195.

http://dx.doi.org/10.1111/j.1600-051X.2005.00786.x

[37] Bergstrom, J. and Floderus-Myrhed, B. (1983) Co-twin control study of the relationship between smoking and some periodontal disease factors. Community Dentistry and Oral Epidemiology, 11, 113-116. http://dx.doi.org/10.1111/j.1600-0528.1983.tb01367.x

[38] Preber, H. and Bergstrom, J. (1985) Occurrence of gingival bleeding in smoker and non-smoker patients. Acta odontologica Scandinavica, 43, 315-320.

[39] Bergstrom, J. and Bostrom, L. (2001) Tobacco smoking and periodontal hemorrhagic responsiveness. Journal of Clinical Periodontology, 28, 680-685.

http://dx.doi.org/10.1034/j.1600-051x.2001.028007680.x

[40] Hanioka, T., Tanaka, M., Ojima, M., Takaya, K., Matsumori, Y. and Shizukuishi, S. (2000) Oxygen sufficiency in the gingiva of smokers and non-smokers with periodontal disease. Journal of Periodontology, 71, 1846-1851. http://dx.doi.org/10.1902/jop.2000.71.12.1846

[41] Mirbod, S.M., Ahing, S.I. and Pruthi, V.K. (2001) Immunohistochemical study of vestibular gingival blood vessel density and internal circumference in smokers and non-smokers. Journal of Periodontology, 72, 1318-1323. http://dx.doi.org/10.1902/jop.2001.72.10.1318

[42] Sonmez, S., Canda, T., Ozkara, E. and Ak, D. (2003) Quantitative evaluation of the vasculature and fibronectin localization in gingival connective tissue of smokers and non-smokers. Journal of Periodontology, 74, 822-830. http://dx.doi.org/10.1902/jop.2003.74.6.822

[43] Rezavandi, K., Palmer, R.M., Odell, E.W., Scott, D.A. and Wilson, R.F. (2002) Expression of ICAM-1 and E-selectin in gingival tissues of smokers and non-smokers with periodontitis. Journal of Oral Pathology \& Medicine, 31, 59-64. http://dx.doi.org/10.1046/j.0904-2512.2001.joptest.doc.x

[44] Baab, D.A. and Oberg, P.A. (1987) The effect of cigarette smoking on gingival blood flow in humans. Journal of Clinical Periodontology, 14, 418-424. http://dx.doi.org/10.1111/j.1600-051X.1987.tb01547.x

[45] Hollinger, J.O., Schmitt, J.M., Hwang, K., Soleymani, P. and Buck, D. (1999) Impact of nicotine on bone healing. Journal of Biomedical Materials Research, 45, 294-301. http://dx.doi.org/10.1002/(SICI)1097-4636(19990615)45: 4<294::AID-JBM3>3.0.CO;2-1

[46] Theiss, S.M., Boden, S.D., Hair, G., Titus, L., Morone, M.A. and Ugbo, J. (2000) The effect of nicotine on gene expression during spine fusion. Spine, 25, 2588-2594. http://dx.doi.org/10.1097/00007632-200010150-00008

[47] Riebel, G.D., Boden, S.D., Whitesides, T.E. and Hutton, W.C. (1995) The effect of nicotine on incorporation of cancellous bone graft in an animal model. Spine, 20, 2198-2202. http://dx.doi.org/10.1097/00007632-199510001-00004

[48] Loos, B.G., Roos, M.T., Schellekens, P.T., Van der Velden, U. and Miedema, F. (2004) Lymphocyte numbers and function in relation to periodontitis and smoking. Journal of Periodontology, 75, 557-564. http://dx.doi.org/10.1902/jop.2004.75.4.557 
[49] Bergstrom, J. and Preber, H. (1986) The influence of cigarette smoking on the development of experimental gingivitis. Journal of Periodontal Research, 21, 668-676. http://dx.doi.org/10.1111/j.1600-0765.1986.tb01504.x

[50] Danielsen, B., Manji, F., Nagelkerke, N., Fejerskov, O. and Baelum, V. (1990) Effect of cigarette smoking on the transition dynamics in experimental gingivitis. Journal of Clinical Periodontology, 17, 159-164. http://dx.doi.org/10.1111/j.1600-051X.1990.tb01080.x

[51] Haffajee, A.D. and Socransky, S.S. (2001) Relationship of cigarette smoking to the subgingival microbiota. Journal of Clinical Periodontology, 28, 377-388. http://dx.doi.org/10.1034/j.1600-051x.2001.028005377.x

[52] Dinsdale, C.R., Rawlinson, A. and Walsh, T.F. (1997) Subgingival temperature in smokers and non-smokers with periodontal disease. Journal of Clinical Periodontology, 24, 761-766. http://dx.doi.org/10.1111/j.1600-051X.1997.tb00194.x

[53] Ketabi, M. and Hirsch, R.S. (1997) The effects of local anesthetic containing adrenaline on gingival blood flow in smokers and non-smokers. Journal of Clinical Periodontology, 24, 888-892. http://dx.doi.org/10.1111/j.1600-051X.1997.tb01207.x

[54] Preber, H., Linder, L. and Bergstrom, J. (1995) Periodontal healing and periopathogenic microflora in smokers and non-smokers. Journal of Clinical Periodontology, 22, 946-952. http://dx.doi.org/10.1111/j.1600-051X.1995.tb01800.x

[55] Stoltenberg, J.L., Osborn, J.B., Pihlstrom, B.L., Herzberg, M.C., Aeppli, D.M., Wolff, L.F. and Fischer, G.E. (1993) Association between cigarette smoking, bacterial pathogens, and periodontal status. Journal of Periodontology, 64, 1225-1230. http://dx.doi.org/10.1902/jop.1993.64.12.1225

[56] Grossi, S.G., Skrepcinski, F.B., DeCaro, T., Zambon, J.J., Cummins, D. and Genco, R.J. (1996) Response to periodontal therapy in diabetics and smokers. Journal of Periodontology, 67, 1094-1102. http://dx.doi.org/10.1902/jop.1996.67.10s.1094

[57] Haffajee, A.D., Cugini, M.A., Dibart, S., Smith, C., Kent Jr., R.L. and Socransky, S.S. (1997) The effect of SRP on the clinical and microbiological parameters of periodontal diseases. Journal of Clinical Periodontology, 24, 324-334. http://dx.doi.org/10.1111/j.1600-051X.1997.tb00765.x

[58] Renvert, S., Dahlen, G. and Wikstrom, M. (1998) The clinical and microbiological effects of non-surgical periodontal therapy in smokers and non-smokers. Journal of Clinical Periodontology, 25, 153-157. http://dx.doi.org/10.1111/j.1600-051X.1998.tb02421.x

[59] Haffajee, A.D. and Socransky, S.S. (2001) Relationship of cigarette smoking to attachment level profiles. Journal of Clinical Periodontology, 28, 283-295. http://dx.doi.org/10.1034/j.1600-051x.2001.028004283.x

[60] Kamma, J.J., Nakou, M. and Baehni, P.C. (1999) Clinical and microbiological characteristics of smokers with early onset periodontitis. Journal of Periodontal Research, 34, 25-33.

http://dx.doi.org/10.1111/j.1600-0765.1999.tb02218.x

[61] Van Winkelhoff, A.J., Bosch-Tijhof, C.J., Winkel, E.G. and van der Reijden, W.A. (2001) Smoking affects the subgingival microflora in periodontitis. Journal of Periodontology, 72, 666-671.

http://dx.doi.org/10.1902/jop.2001.72.5.666

[62] Van der Velden, U., Varoufaki, A., Hutter, J.W., Xu, L., Timmerman, M.F., Van Winkelhoff, A.J. and Loos, B.G. (2003) Effect of smoking and periodontal treatment on the subgingival microflora. Journal of Clinical Periodontology, 30, 603-610. http://dx.doi.org/10.1034/j.1600-051X.2003.00080.x

[63] Darby, I.B., Hodge, P.J., Riggio, M.P. and Kinane, D.F. (2005) Clinical and microbiological effect of scaling and root planing in smoker and non-smoker chronic and aggressive periodontitis patients. Journal of Clinical Periodontology, 32, 200-206. http://dx.doi.org/10.1111/j.1600-051X.2005.00644.x

[64] Ryder, M.I. (2007) The influence of smoking on host responses in periodontal infections. Periodontology, 43, 267-277. http://dx.doi.org/10.1111/j.1600-0757.2006.00163.x

[65] Hanes, P.J., Schuster, G.S. and Lubas, S. (1991) Binding, uptake, and release of nicotine by human gingival fibroblasts. Journal of Periodontology, 62, 147-152. http://dx.doi.org/10.1902/jop.1991.62.2.147

[66] Raulin, L.A., McPherson III, J.C., McQuade, M.J. and Hanson, B.S. (1988) The effect of nicotine on the attachment of human fibroblasts to glass and human root surfaces in vitro. Journal of Periodontology, 59, 318-325. http://dx.doi.org/10.1902/jop.1988.59.5.318

[67] Ryder, M.I., Fujitaki, R., Johnson, G. and Hyun, W. (1998) Alterations of neutrophil oxidative burst by in vitro smoke exposure: Implications for oral and systemic diseases. Annals of Periodontology, 3, 76-87.

http://dx.doi.org/10.1902/annals.1998.3.1.76

[68] Golub, L.M., Lee, H.M., Ryan, M.E., Giannobile, W.V., Payne, J. and Sorsa, T. (1998) Tetracyclines inhibit connective tissue breakdown by multiple non-antimicrobial mechanisms. Advances in Dental Research, 12, 12-26. http://dx.doi.org/10.1177/08959374980120010501

[69] Li, Q.Y., Zhao, H.S., Meng, H.X., Zhang, L., Xu, L., Chen, Z.B., Shi, D., Feng, X.H. and Zhu, X.L. (2004) Association analysis between interleukin-1 family polymorphisms and generalized aggressive periodontitis in a Chinese population. Journal of Periodontology, 75, 16271635. http://dx.doi.org/10.1902/jop.2004.75.12.1627

[70] Petropoulos, G., McKay, I.J. and Hughes, F.J. (2004) The association between neutrophil numbers and interleukin$1 \alpha$ concentrations in gingival crevicular fluid of smokers and non-smokers with periodontal disease. Journal of Clinical Periodontology, 31, 390-395. http://dx.doi.org/10.1111/j.1600-051x.2004.00489.x

[71] MacNee, W., Wiggs, B., Belzberg, A.S. and Hogg, J.C. (1989) The effect of cigarette smoking on neutrophil kinetics in human lungs. New England Journal of Medicine, 321, 924-928. http://dx.doi.org/10.1056/NEJM198910053211402

[72] Gunsolley, J.C., Pandey, J.P., Quinn, S.M., Tew, J. and Schenkein, H.A. (1997) The effect of race, smoking and immunoglobulin allotypes on IgG subclass concentrations. 
Journal of Periodontal Research, 32, 381-387. http://dx.doi.org/10.1111/j.1600-0765.1997.tb00548.x

[73] Quinn, S.M., Zhang, J.B., Gunsolley, J.C., Schenkein, H.A. and Tew, J.G. (1998) The influence of smoking and race on adult periodontitis and serum IgG2 levels. Journal of Periodontology, 69, 171-177.

http://dx.doi.org/10.1902/jop.1998.69.2.171

[74] Payne, J.B., Johnson, G.K., Reinhardt, R.A., Dyer, J.K., Maze, C.A. and Dunning, D.G. (1996) Nicotine effects on $\mathrm{PGE}_{2}$ and IL- $1 \beta$ release by LPS-treated human monocytes. Journal of Periodontal Research, 31, 99-104. http://dx.doi.org/10.1111/j.1600-0765.1996.tb00470.x

[75] Lannan, S., McLean, A., Drost, E., Gillooly, M., Donaldson, K., Lamb, D. and MacNee, W. (1992) Changes in neutrophil morphology and morphometry following exposure to cigarette smoke. International Journal of Experimental Pathology, 73, 183-191.
[76] Selby, C., Drost, E., Brown, D., Howie, S. and MacNee, W. (1992) Inhibition of neutrophil adherence and movement by acute cigarette smoke exposure. Experimental Lung Research, 18, 813-827. http://dx.doi.org/10.3109/01902149209031709

[77] Ryder, M.I., Wu, T.C., Kallaos, S.S. and Hyun, W. (2002) Alterations of neutrophil f-actin kinetics by tobacco smoke: Implications for periodontal diseases. Journal of Periodontal Research, 37, 286-292. http://dx.doi.org/10.1034/j.1600-0765.2002.01034.x

[78] McGuire, J.R., McQuade, M.J., Rossmann, J. A., Garnick, J.J., Sutherland, D.E., Scheidt, M.J. and Van Dyke, T.E. (1989) Cotinine in saliva and gingival crevicular fluid of smokers with periodontal disease. Journal of Periodontology, 60, 176-181. http://dx.doi.org/10.1902/jop.1989.60.4.176 